\title{
Analysis of Spatial and Temporal Distribution Characteristics of Land Desertification Based on GIS and Remote Sensing Images
}

\author{
Li Cui \\ School of Prospecting and Surveying Engineering, Changchun Institute of Engineering, ChangChun 130021, China \\ Correspondence should be addressed to Li Cui; gcrz2019ch@ccit.edu.cn
}

Received 21 September 2021; Accepted 9 November 2021; Published 13 December 2021

Academic Editor: Hai Dong

Copyright (c) $2021 \mathrm{Li}$ Cui. This is an open access article distributed under the Creative Commons Attribution License, which permits unrestricted use, distribution, and reproduction in any medium, provided the original work is properly cited.

\begin{abstract}
Due to the complex geographical situation in China, in this paper, the area of land desertification is $98.5 \%$ of the total land desertification area in China. Based on the measured data of GIS and remote sensing images, we will discuss the spatial and temporal distribution characteristics of land desertification in China by calculating standardized precipitation evapotranspiration index (SPEI) and normalized vegetation index and establishing the CA model. The results show the following. (1) The trend of desertification in China has decreased as a whole, and the percentage of nondesertification has increased from $36.91 \%$ in 1991 to $44.46 \%$ in 2020 , an increase of $7.55 \%$. Extremely severe desertification increased from $21.72 \%$ to $24.25 \%$, an increase of $2.53 \%$. (2) The drought situation in the study area gradually improved, and the change trend of SPEI decreased by $74 \%$. (3) In recent ten years (2011-2020), the vegetation grew well gradually, and it was in the best state in 2018 . The NDVI index value increased by $5.9 \%$ compared with the average value in this decade. (4) The model designed by us works very well, and the results of simulating and testing the Three Rivers Source region are very little different from the actual situation, which meets our research requirements.
\end{abstract}

\section{Introduction}

The Earth, on which human beings depend, is facing severe environmental challenges, such as air pollution, soil erosion, and garbage disposal, which threaten human survival and cause continuous and bad effects. Due to the vast territory and complex natural geography in China, the problem of land desertification is particularly prominent in some areas of China, and the desertified land accounts for $27.2 \%$ of the national area. It is precisely because the population affected by desertification in China is the largest, and people are deeply eroded by wind and sand, so the research methods and prevention means of land desertification in China are relatively mature. GIS and remote sensing images are commonly used technologies. By analyzing the spatial and temporal distribution characteristics of land desertification, we can choose a more optimized method to guide the desertification control. Remote sensing monitoring of desertification land in northern China in 2000 showed that desertification land developed rapidly [1], and desertification land in some dry farming areas and farming-pastoral ecotone areas was obviously reversed. Land cover, normalized difference vegetation index, cropland, woodland, and grassland maps were developed using remote sensing data and GIS monitoring [2]. In reference [3], GIS was used to evaluate land desertification, and wetness index, windy days, soil texture, and surface vegetation coverage were selected as evaluation factors of desertification sensitivity. Literature [4] found that desertification is serious from TM images of GIS, which is related to physical factors and differences in land use patterns. Literature [5] described the structural changes and development characteristics of desertification in Yanchi in detail through GIS and database. Literature [6] obtained the data of temporal and spatial change and differentiation model of desertification land around Qinghai and predicted the development trend of desertification in the next 20 years. Literature [7] described a GIS-based software tool for qualitative assessment of desertification risk. Through RS and GIS dynamic monitoring [8], it is found that land desertification is widespread in Longyangxia reservoir area of Qinghai Province. Literature [9] used Google Maps API, data cache, and other 
technologies to demonstrate the desertification situation in Lurgai area. Gad and Lotfy [10] produced ETM satellite imagery and geological and soil maps of the whole of Egypt, with a scale of $1: 1000000$. Literature [11] used GIS and ecosystem models to assist in assessing and mapping desertification. Literature [12] interpreted TM remote image of oasis lake area to analyze desertification evolution and simulated desertification dynamics by arc object module and cellular automata model. The spatial analysis function of ArcGIS 9.3 software [13] is used to evaluate the desertification index in southern Iraq, and the integrated remote sensing and GIS are used to evaluate the desertification environmentally sensitive areas. Literature [14] studied the dynamics of desertification and examined the accuracy of non-out-of-scope classification methods. According to RS and GIS information of Yijinhuoluo County in Muwu Sandy Land, $\mathrm{Xu}$ [15] established the estimation model of vegetation coverage rate and biomass. Desertification exists in some areas. This paper discusses the spatial and temporal distribution characteristics of land desertification in China by using the measured data of GIS and remote sensing images, calculating standardized precipitation evapotranspiration index (SPEI) and normalized vegetation index and establishing the CA model. Through the analysis of spatial and temporal distribution characteristics of land desertification, a more optimized method is selected to guide the desertification control.

\section{Study the Relevant Theoretical Basis}

Geographic Information System (GIS) uses GIS tools (or platforms) to display these data in the form of intuitive and effective maps and to display and describe its geographic analysis functions. GIS [16] is usually complementary to GPS technology [17] and satellite remote sensing technology [18]. It helps people in need to complete a series of work such as modeling, prediction, and detection. Now, GIS is no longer a distant "high-tech" product; it is quietly gradually into the public life. Everyone can easily use GIS service [19] to obtain geographical knowledge and data.

Remote sensing technology [20] is not a new detection technology in recent years. As early as 1960s, this technology has been produced and put into use in the exploration and monitoring of the Earth, which is used to obtain a large number of resources and environmental information. Because of the maturity of technology and the cheapness, convenience, and richness of obtaining data, it has been widely used in agriculture, forestry, ocean, geography, and other fields, which is closely related to people. Remote sensing technology uses photography to obtain images [21] to improve the accuracy of GIS and reduce the map update cycle [22]:

(1) With the help of ternary wavelet transform [23], the formula is as follows:

$$
\begin{aligned}
& D A(x, y)\langle D B(x, y), D A(x, y)\rangle D B(x, y), \\
& R(x, y)=\left\{\begin{array}{l}
A(x, y) \\
B(x, y)
\end{array}\right.
\end{aligned}
$$

(2) Remote sensing images are corrected geometrically [24] to reduce the effects of distortion. The general flow of geometric correction is shown in Figure 1.

In Figure 1, because the remote sensing image will be geometrically deformed by the imaging lens, almost all kinds of remote sensing images need to be geometrically corrected to reduce the influence of distortion on data acquisition and generate more accurate maps or graphics that meet the requirements.

The geometric registration [25] formula is as follows:

$$
\left\{\begin{array}{l}
X=a_{0}+a_{1} x+a_{2} x+a_{3} x+\cdots \cdots \\
Y=b_{0}+b_{1} x+b_{2} x+b_{3} x+\cdots \cdots
\end{array}\right.
$$

2.1. Introduction to ERADS Software. ERADS IMAGINE V9.2 developed by American ERADS Company is a powerful and easy-to-operate ERADS IMAGINE V9.2 product. This software product is technically mature and integrates the geographic information system (GIS) and remote sensing image processing. A great feature of this software is that it has a good and sufficient interface, which can communicate stably with other software (such as ARC/ INFO, Dbase, and Autocad), share functions and data, and greatly improve the usability of this product. Software versions are constantly updated and maintained, including the latest image processing algorithms, and adaptability is extremely strong. The functional system of the product is shown in Figure 2.

2.2. Cellular Automata (CA). Cellular automaton is a dynamic system.

Represent a model with a formula as follows:

$$
A=(C, S, N, R) \text {. }
$$

Represent models in sets as follows:

$$
S^{t+1}=f\left(S^{t}, N\right) .
$$

Formula (5) is a function that can explain the basic principle of cellular automata (CA). We use sets to express the cellular automata (CA) model. This expression is concise and clear, and the model is more intuitive. In particular, $S$ is a finite set, which also represents cell state, $N$ is the cell domain, variable $t$ represents the time, and letter $f$ represents the local transformation rule.

The structure diagram of the model is shown in Figure 3.

\subsection{Drought Evaluation Indicators}

2.3.1. Standardized Precipitation Evapotranspiration Index (SPEI). Standardized precipitation evapotranspiration index (SPEI) can help us to analyze the dynamic process of land desertification at different levels, which is of great significance to the study of this paper. The formula for SPEI is as shown in equation (5) where $w=\sqrt{-2 \ln (P)}$, $C_{0}=2.51552, \quad C_{1}=0.80285, \quad C_{2}=0.01033, \quad d_{1}=1.43279$, $d_{2}=0.18927$, and $d_{3}=0.00131$ : 


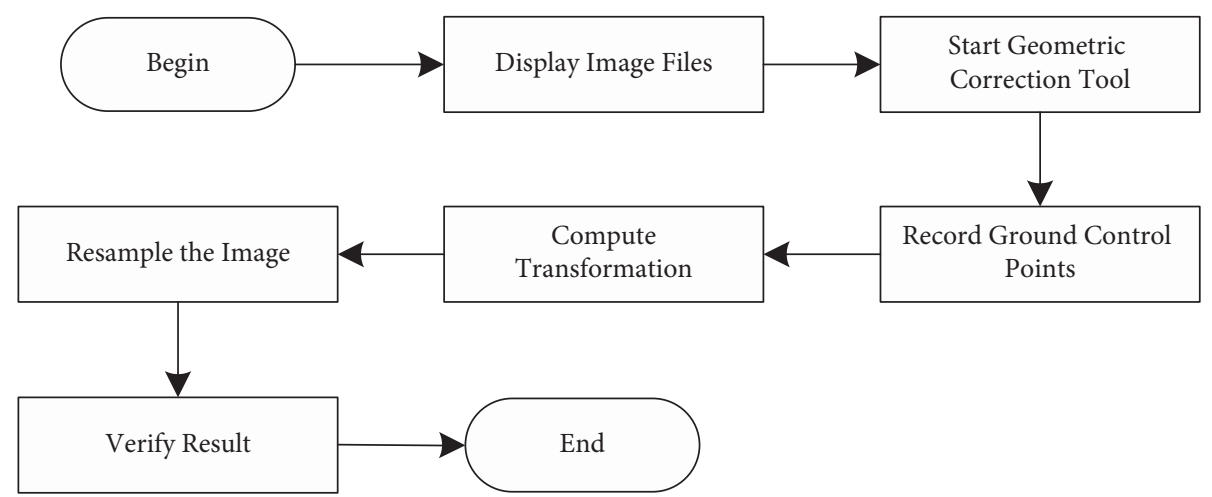

Figure 1: Image geometric correction.

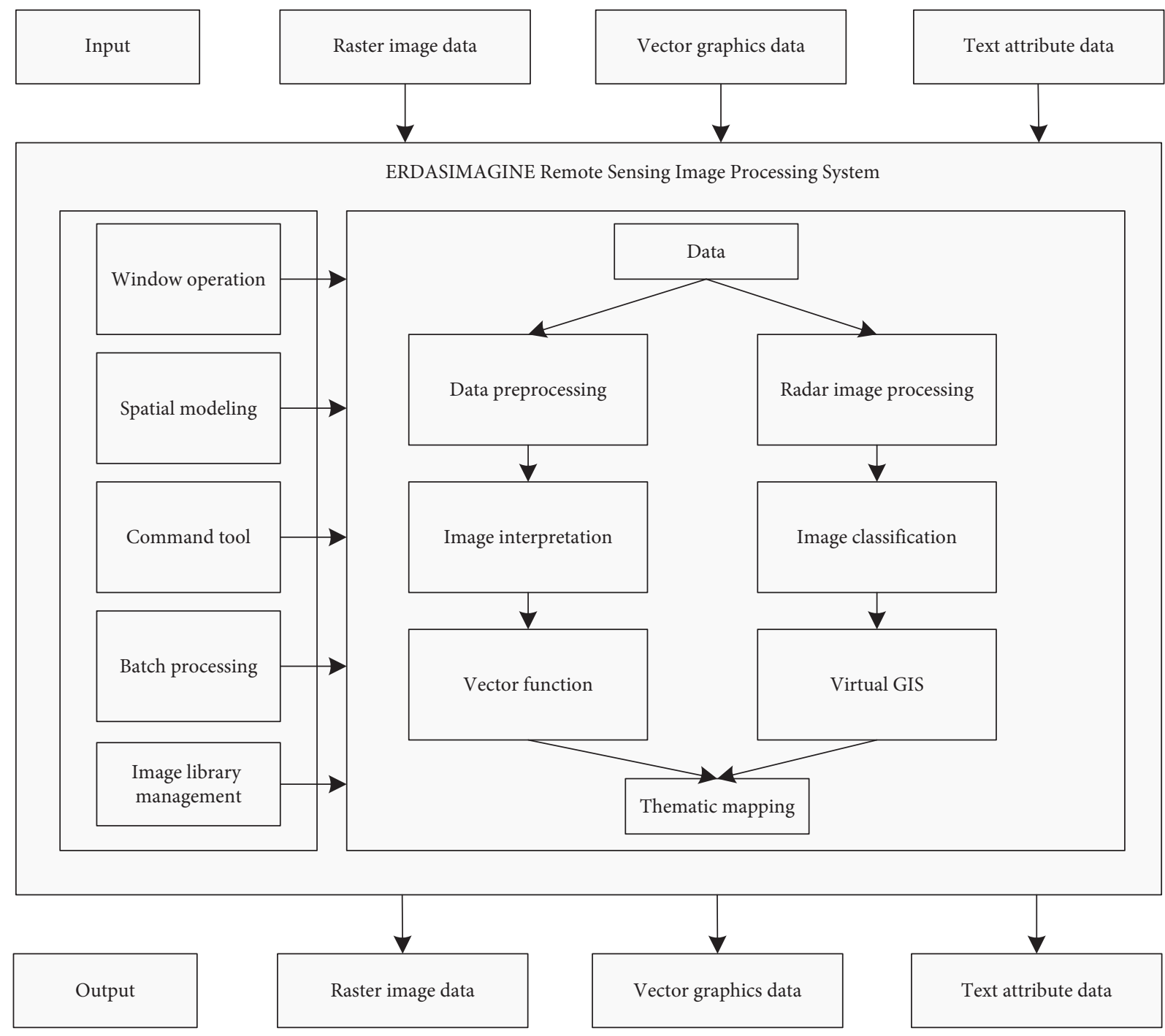

FIGURE 2: Block diagram of ERADS IMAGINE V9.2. 


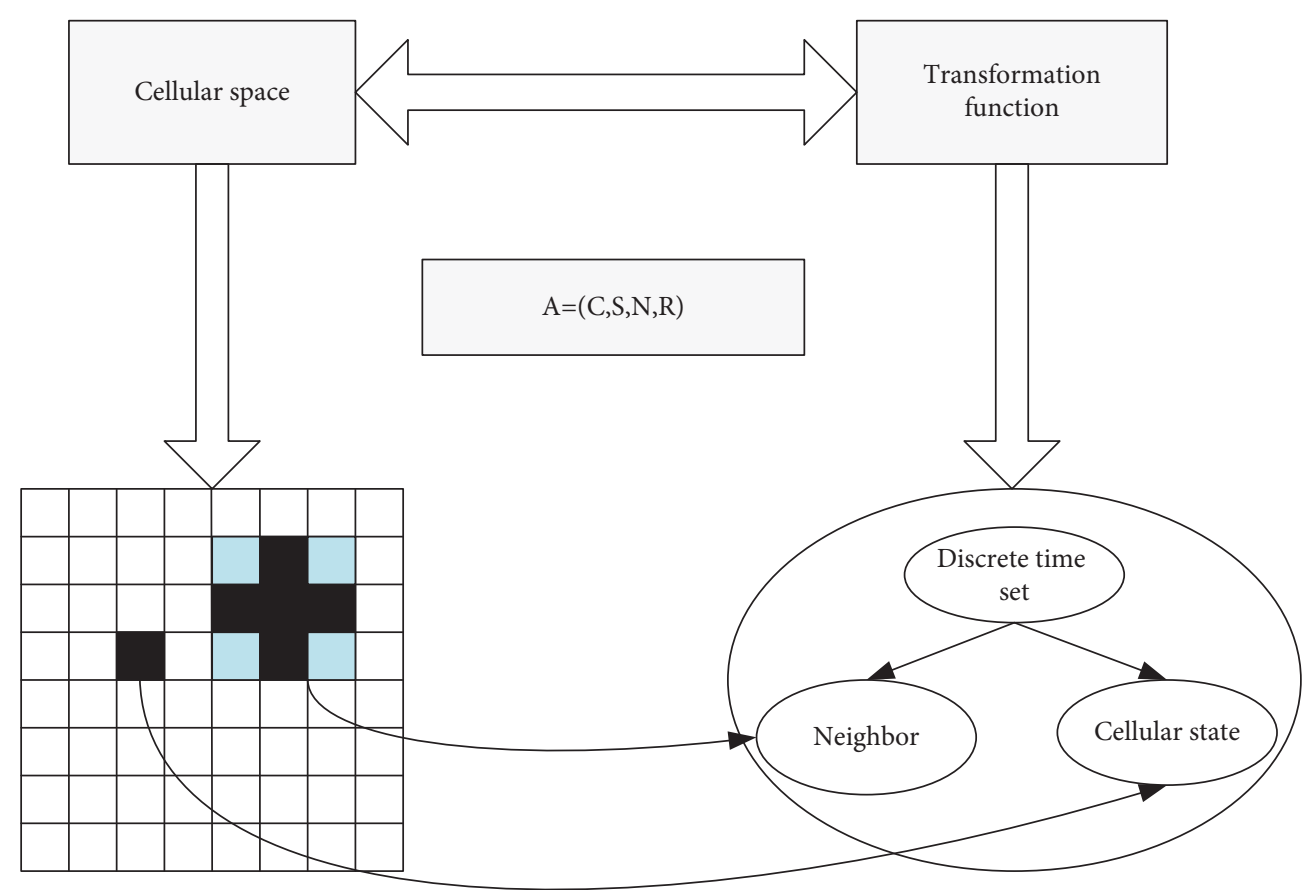

Figure 3: Composition of the cellular automata (CA) model.

$$
\text { SPEI }=w-\frac{C_{0}+C_{1} w+C_{2} w^{2}}{1+d_{1} w+d_{2} w^{2}+d_{3} w^{3}} .
$$

When $P>0.5, P$ is replaced by $1-P$, and the value is reversed positively and negatively. $F(x)$ is a function of water surplus and deficiency:

$$
\begin{gathered}
P=1-F(x), \\
F(x)=\left[1+\left(\frac{\alpha}{x-\gamma}\right) \beta\right]^{-1} .
\end{gathered}
$$

Potential evapotranspiration is calculated by the following formula:

$$
E_{d}=\frac{0.408 \Delta\left(R_{n}-G\right)+\gamma 900 / T_{a}+273 u_{2}\left(e_{s}+e_{a}\right)}{\Delta+\gamma\left(1+0.34 u_{2}\right)} .
$$

2.3.2. Ratio of Drought Stations $\left(P_{j}\right)$. The calculation formula of arid station frequency ratio is as follows:

$$
P_{j}=\frac{m_{j}}{M} \times 100 \% \text {. }
$$

2.3.3. Drought Intensity $\left(S_{j}\right)$. Drought intensity can evaluate the severity of drought. The larger the SPI value in the formula, the more serious the drought it represents. The specific calculation formula is shown as follows:

$$
S_{j}=\left|\frac{1}{m} \sum_{i=1}^{m} \operatorname{SPI}_{i}\right| \text {. }
$$

2.4. Normalized Vegetation Index (NDVI). Using remote sensing image data and GIS, this study can obtain the spatial distribution map of vegetation growth in China's land desert areas, then calculate the normalized vegetation index (NDVI), and then analyze and map it. We can analyze the desertification and ecosystem in China according to the monitored vegetation coverage and growth, which is of great significance. The greater the NDVI, the denser the vegetation; the smaller the NDVI, the more sparse the vegetation. The calculation formula is shown as follows:

$$
\mathrm{NDVI}=\frac{\text { Band } 2-\text { Band } 1}{\text { Band } 2+\text { Band } 1}
$$

China has a vast territory and a complex and changeable geographical situation. Due to the actual situation and technical reasons, this study cannot fully discuss the national land desertification situation. Therefore, we mainly choose the northern region of China as the study area, and the land desertification in the northern region accounts for $98.5 \%$ of the total land desertification area in China, namely, Shaanxi, Ningxia, Hebei, Gansu, Qinghai, Inner Mongolia, Xinjiang, and Tibet. These provinces have high research value in terms of geography and climate, and the rest provinces account for $1.5 \%$, which are classified into one category because they are too scattered, so they only do brief discussion and research. The specific distribution map of 8 provinces of land desertification is shown in Figure 4.

The data obtained in this study include land use map, basic statistical data, and second-hand data. The specific data processing specifications are shown in Table 1. 


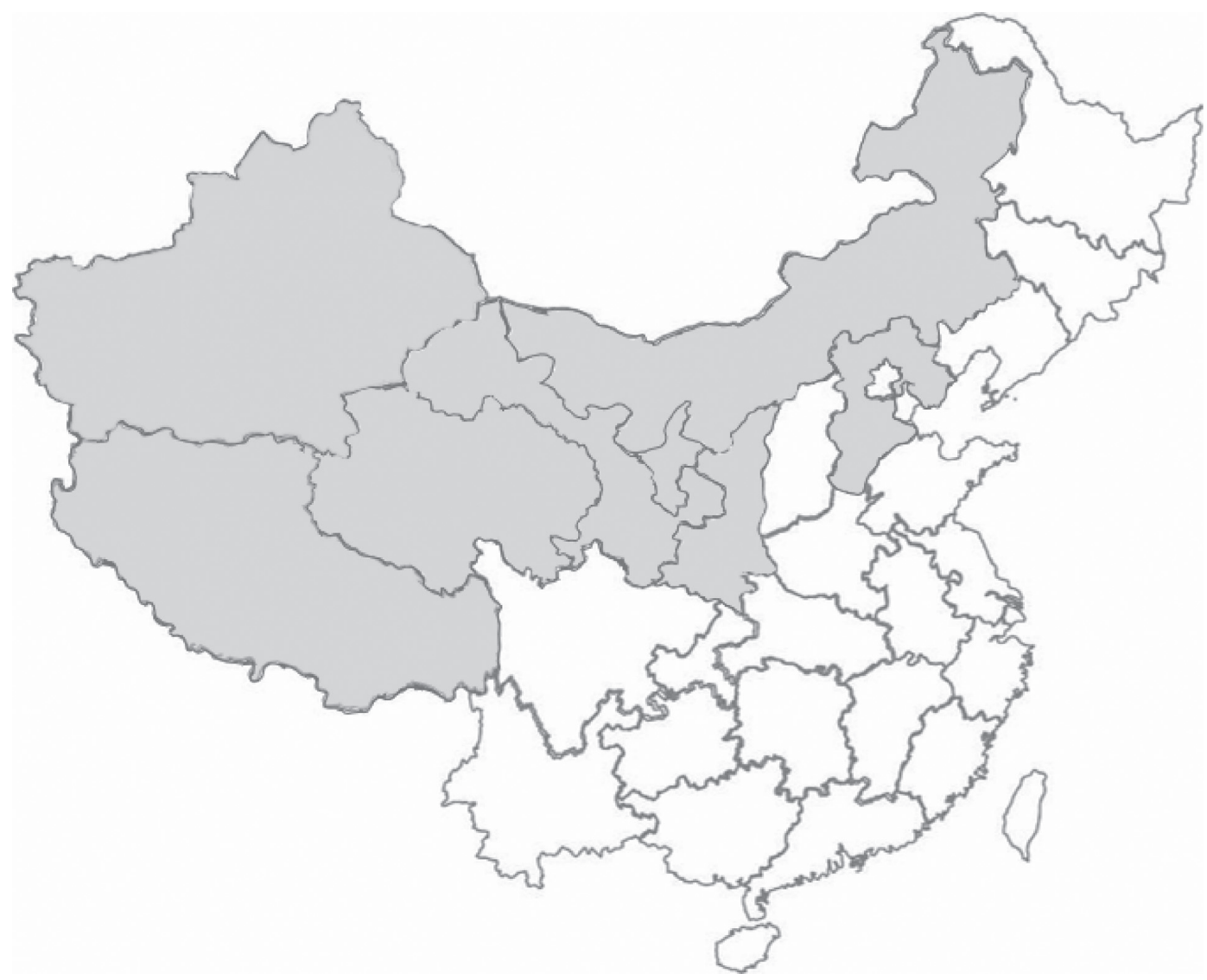

Figure 4: Main land desertification provinces.

TABLE 1: Data processing specifications.

\begin{tabular}{lccc}
\hline Time series & Spatial distribution rate $(\mathrm{m})$ & Storage form & Model data format \\
\hline Year & 30 & Grid & Binary data (ASCII code format) \\
\hline
\end{tabular}

\section{Analysis of Land Desertification Degree}

3.1. Analysis of Various Land Types. We obtain the land type change data of desertification in northern China, and we can find that the land vegetation types are basically divided into desert, Gobi, bare land, sandy land, grassland, cultivated vegetation, meadow, alpine vegetation, coniferous forest, and broad-leaved forest. Desertification land accounts for the heaviest proportion in the figure. The details are shown in Figure 5.

There are basically five types of land use, as shown in Figure 6.

\subsection{Classification and Classification System of Desertification.} In the study, the land desertification classification in the study area is convenient for researchers to make reasonable judgments and can quickly determine the degree and current situation of desertification in the region. We introduce Feng Yusun's evaluation system to classify desertification, as shown in Table 2.

The desertification classification system is shown in Table 3 .
3.3. Temporal and Spatial Variation Characteristics of Desertification Land. We divide the period 1991-2020 into three time periods: 1991-2000, 2001-2010, and 2011-2020. The specific desertification situation is shown in Table 4 .

According to the above table, the general trend of land desertification in northern China is gradually decreasing, and the percentage of nondesertification has increased from $36.91 \%$ in 1991 to $44.46 \%$ in 2020 , an increase of $7.55 \%$. However, the extremely severe desertification increased from $21.72 \%$ to $24.25 \%$, an increase of $2.53 \%$. This shows that the ecological environment in desertification areas in China is gradually improving, but it is inevitable that some areas are not only not improving but also aggravating the trend of land desertification, which deserves the attention of local relevant departments, and more control and prevention should be given to land desertification. We need to assess the situation of land desertification from multiple angles and aspects, instead of measuring it with one or two unilateral factors.

3.3.1. Regional Drought Dynamics. Drought is a serious meteorological disaster. Due to the greenhouse effect and the influence of various human activities, the economic loss 


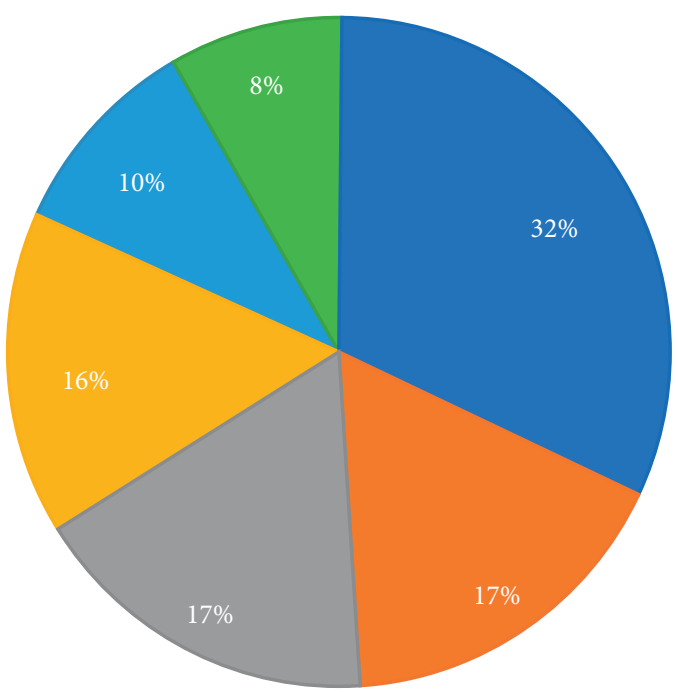

Desert and others (Gobi, bare land and sandy land)

Grassland

Cultivated vegetation

Meadow, alpine vegetation

Coniferous forest

Broad-leaved forest

FIGURE 5: Various land types in northern China.

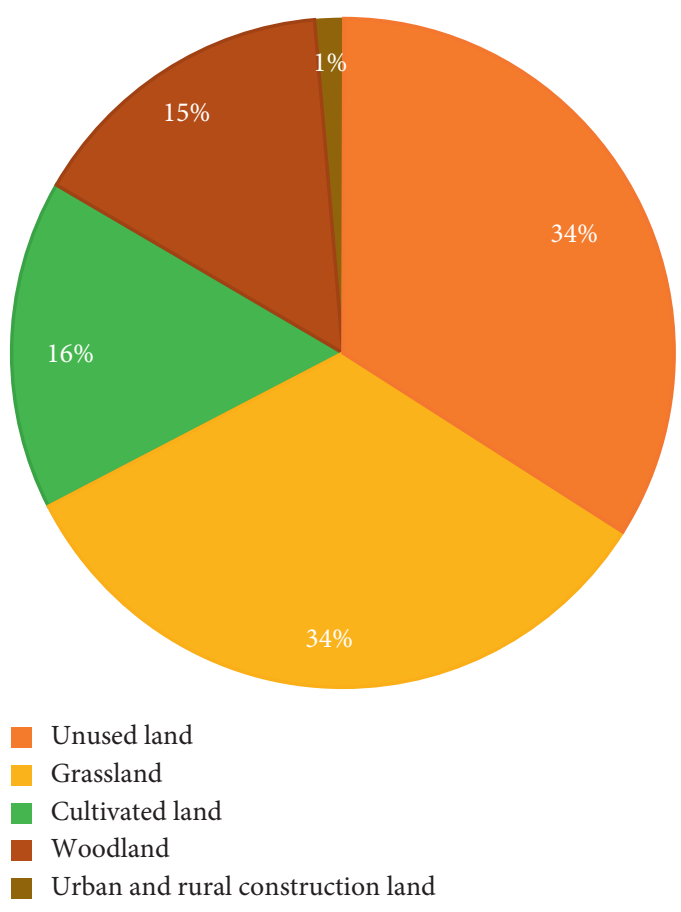

FIGURE 6: Land use types in northern China.

caused by drought disasters in the world is as high as $43 \%$ every year, which accounts for the largest proportion of all natural disaster losses.

(1) The annual and seasonal changes of SPEI in the northern study area decreased as a whole, with a decrease area of $74 \%$ and a significant decrease area of $43 \%$. In some areas, the increase area is $26 \%$, and the significant increase area is $6 \%$.

As shown in Table 5, it is a statistical table of SPEI and drought grade change trend in northern study area.

(2) Drought stations in different dry and wet areas from 1966 to 2020 are shown in Figure 7.

We can find from the figure that the distribution of arid station frequency ratio in humid area is uneven, and the arid station frequency ratio is the least in some regional droughts. The ratio of drought stations and drought intensity in humid and semihumid areas showed an increasing trend. The ratio of arid stations and drought intensity in arid and semiarid areas showed a decreasing trend.

(3) The tendency rate of SPI in different dry and wet areas from 1966 to 2020 is shown in Figure 8.

According to the analysis of SPI propensity rate in the line chart, we can obviously observe that SPI propensity rate increases in different dry and wet areas in different seasons.

\subsubsection{Changes in Desertification Vegetation Growth.} Figure 9 shows the average NDVI trend chart.

As shown in Figure 10, it is a change map of the vegetation index.

Vegetation in desertification areas has gradually grown well in recent ten years. In 2018, the state was the best, and the NDVI index value increased by $5.9 \%$ compared with the average value in this decade. The ecosystem of desert areas in northern China has gradually improved, and the trend of desertification has been gradually controlled.

3.3.3. Dynamic Simulation Analysis of Desertification in the Source Region of the Three Rivers. Because of the vast land in northern China, the development status of each region is different, so it is difficult to carry out dynamic simulation and prediction analysis uniformly. Considering the money cost, time cost, and difficulty of data extraction, we choose Sanjiangyuan region, which is located in the south of Qinghai Province and the hinterland of Qinghai-Tibet Plateau, as a regional dynamic simulation and prediction analysis of land desertification. As shown in Figure 11, it is the geographical location map of the Sanjiangyuan region.

3.4. Data Preparation and Preprocessing. To simulate the evolution of desertification, we need to collect various spatial data and statistical data, use ERADS software to preprocess the original data, extract important data from GIS and remote sensing images, and standardize the data after processing. This processing can effectively prevent the original data measured by us from being affected by interference factors such as human factors and equipment factors and ensure the accuracy of experimental results.

There are two data standardization methods when preprocessing data. 
Table 2: Feng Yusun's desertification classification system.

\begin{tabular}{|c|c|c|c|c|}
\hline Characteristic & Serious & Strongly developing & In development & Potential \\
\hline $\begin{array}{l}\text { Proportion of } \\
\text { desertification land }\end{array}$ & $>50 \%$ & $25-50 \%$ & $5-25 \%$ & $<5 \%$ \\
\hline $\begin{array}{l}\text { Expansion rate of } \\
\text { desertification land }\end{array}$ & $>40 \%$ & $40-20 \%$ & $5-20 \%$ & $<5 \%$ \\
\hline Dune type & $\begin{array}{l}\text { Large area crescent } \\
\text { dunes or dune } \\
\text { chains }\end{array}$ & $\begin{array}{l}\text { Beam-shaped dunes are dominant } \\
\text { and crescent-shaped dunes } \\
\text { occasionally appear }\end{array}$ & $\begin{array}{l}\text { Beam-shaped sand dunes, } \\
\text { shrub sand piles, and sand } \\
\text { ridges intersect }\end{array}$ & $\begin{array}{c}\text { There is basically no } \\
\text { quicksand } \\
\text { distribution }\end{array}$ \\
\hline $\begin{array}{l}\text { Relative height of dune } \\
\text { undulation (M) }\end{array}$ & $>25$ & $10-25$ & $5-10$ & $<5$ \\
\hline Degree of dune activity & Mobile dune & Semimobile dune & Semifixed dune & Fixed dune \\
\hline $\begin{array}{l}\text { Vegetation coverage } \\
\text { on sand dunes }\end{array}$ & $<15 \%$ & $15-30 \%$ & $30-50 \%$ & $>50 \%$ \\
\hline
\end{tabular}

TABLE 3: Classification system of land desertification in northern China.

\begin{tabular}{|c|c|c|c|c|c|c|}
\hline $\begin{array}{l}\text { Types of } \\
\text { desertification }\end{array}$ & $\begin{array}{l}\text { Vegetation } \\
\text { coverage }\end{array}$ & $\begin{array}{l}\text { Wind erosion } \\
\text { thickness of land } \\
(\mathrm{cm})\end{array}$ & $\begin{array}{l}\text { Aeolian deposition } \\
\text { of land }(\mathrm{cm})\end{array}$ & $\begin{array}{l}\text { Soil erosion } \\
\left(1 / \mathrm{hm}^{2} \cdot \mathrm{y}\right)\end{array}$ & $\begin{array}{c}\text { Population } \\
\text { overload rate }(\%)\end{array}$ & $\begin{array}{c}\text { Livestock } \\
\text { overload rate (\%) }\end{array}$ \\
\hline Mild desertification & $40-60 \%$ & $<5$ & $<5$ & $<0.5$ & $-50 \sim 31$ & $-50 \sim 31$ \\
\hline $\begin{array}{l}\text { Moderate } \\
\text { desertification }\end{array}$ & $25-40 \%$ & $5 \sim 10$ & $5 \sim 10$ & $0.5 \sim 1.0$ & $-31 \sim 0$ & $-31 \sim 0$ \\
\hline Severe desertification & $10-25 \%$ & $10 \sim 20$ & $10 \sim 20$ & $1.0 \sim 3.0$ & $0 \sim 31$ & $0 \sim 31$ \\
\hline $\begin{array}{l}\text { Extremely severe } \\
\text { desertification }\end{array}$ & $<10 \%$ & $>20$ & $>20$ & $>3.0$ & $>31$ & $>31$ \\
\hline
\end{tabular}

TABle 4: Desertification land area and percentage of different grades from 1991 to 2020.

\begin{tabular}{|c|c|c|c|c|c|c|}
\hline \multirow[b]{2}{*}{ Type } & \multicolumn{2}{|c|}{$1991-2000$} & \multicolumn{2}{|c|}{$2001-2010$} & \multicolumn{2}{|c|}{$2011-2020$} \\
\hline & Area $\left(10^{4} \mathrm{~km}^{2}\right)$ & Percentage (\%) & Area area $/ 10^{4} \mathrm{~km}^{2}$ & Percentage (\%) & $\begin{array}{c}\text { Area area/ } \\
10^{4} \mathrm{~km}^{2}\end{array}$ & $\begin{array}{c}\text { Percentage } \\
(\%)\end{array}$ \\
\hline Nondesertification & 196.12 & 36.91 & 213.73 & 40.23 & 236.22 & 44.46 \\
\hline Mild desertification & 67.99 & 12.80 & 60.57 & 11.40 & 50.24 & 9.46 \\
\hline Moderate desertification & 50.21 & 9.45 & 45.69 & 8.60 & 42.84 & 8.06 \\
\hline Severe desertification & 101.17 & 19.04 & 94.22 & 17.73 & 72.98 & 9.46 \\
\hline Extremely severe desertification & 115.40 & 21.72 & 116.93 & 22.01 & 128.84 & 24.25 \\
\hline
\end{tabular}

TABLE 5: SPEI and statistics of drought change trend.

\begin{tabular}{lcccccccc}
\hline \multirow{2}{*}{$\begin{array}{l}\text { Project } \\
\end{array}$} & \multicolumn{3}{c}{ Variation trend of SPEI in years and seasons } & \multicolumn{3}{c}{$\begin{array}{c}\text { Variation trend of different drought } \\
\text { grades }\end{array}$} \\
& Year (\%) & Spring (\%) & Summer (\%) & Autumn (\%) & Winter (\%) & Mild (\%) & Moderate (\%) & Extreme (\%) \\
\hline Increasing trend & 26 & 19 & 36 & 33 & 48 & 78 & 81 \\
Significant increase & 6 & 0 & 1 & 1 & 6 & 17 & 38 & 49 \\
Reducing trend & 74 & 81 & 64 & 67 & 52 & 22 & 19 & 31 \\
Significant reduction & 43 & 43 & 12 & 17 & 7 & 0 & 0 \\
\hline
\end{tabular}

(1) Min-max standardization method is as follows:

$$
y_{i}=\frac{x_{i}-x_{\min }}{x_{\max }-x_{\min }} .
$$

(2) $Z$-score standardization method is as follows:

$$
y_{i}=\frac{x_{i}-u}{s} .
$$

In this paper, the min-max standardization method is adopted, as shown in Table 6, which is partially standardized data.
The CA model selected in this study is based on raster data. The realization of the CA model should first define the state and type of land, then monitor the desertification land in the source region of the Three Rivers, and comprehensively judge the influence degree of desertification by various indicators. We select the data in 2000 to run the model, compare the simulated desertification results in 2018 with the actual land desertification distribution in 2018, then constantly adjust and run the model, and finally select the more suitable model parameters for evolutionary simulation analysis. 


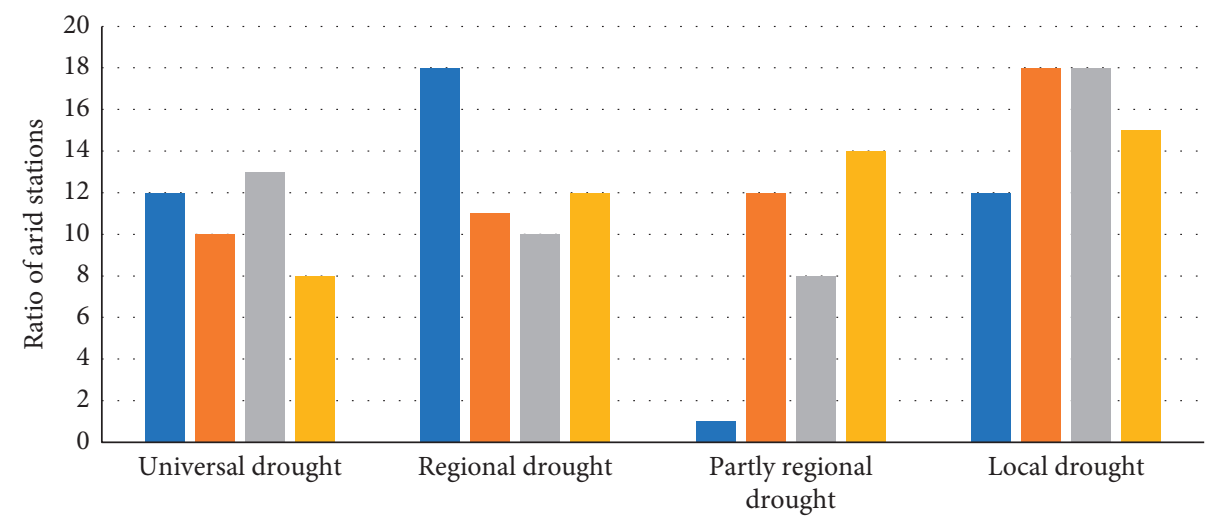

Different arid areas

- Humid area

- Semi-humid area

- Semi-arid area

- Arid area

Figure 7: Ratio of arid stations in different dry and wet areas from 2006 to 2020.

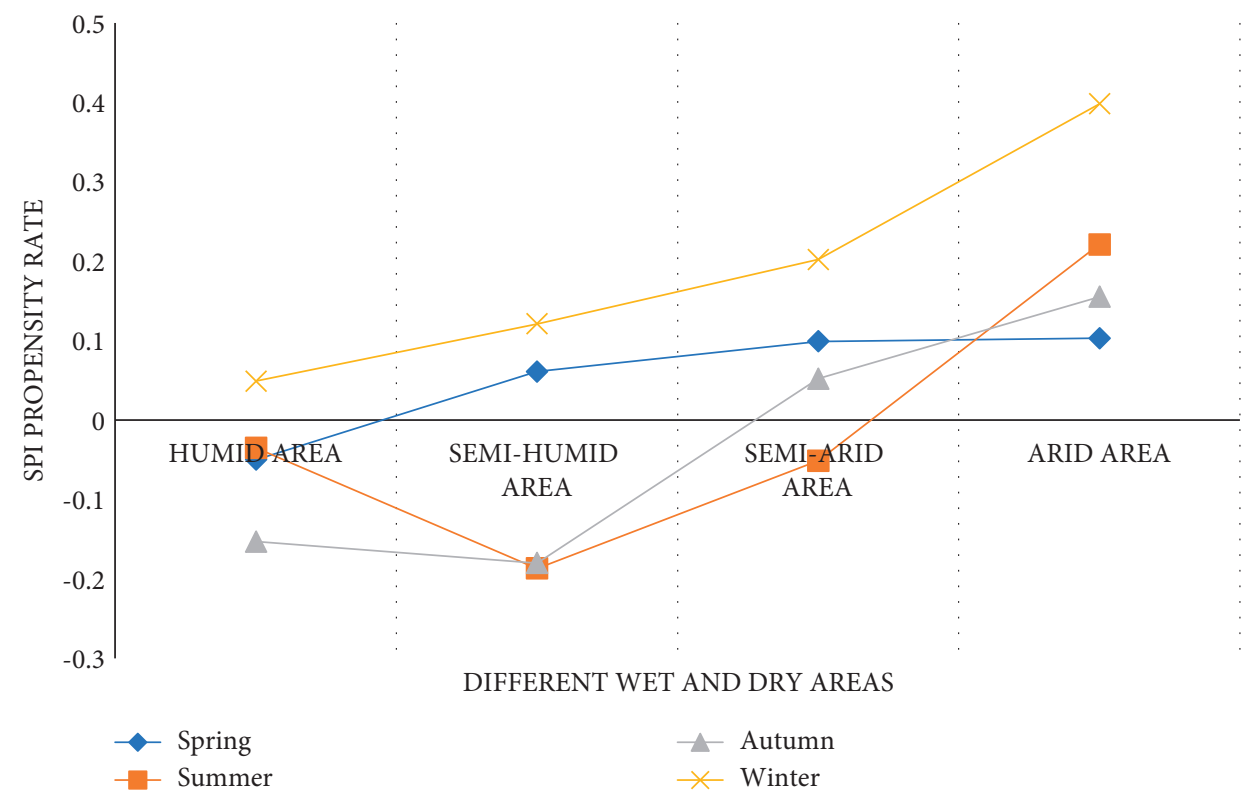

FIGURE 8: SPI tendency rate in different dry and wet areas in four seasons.

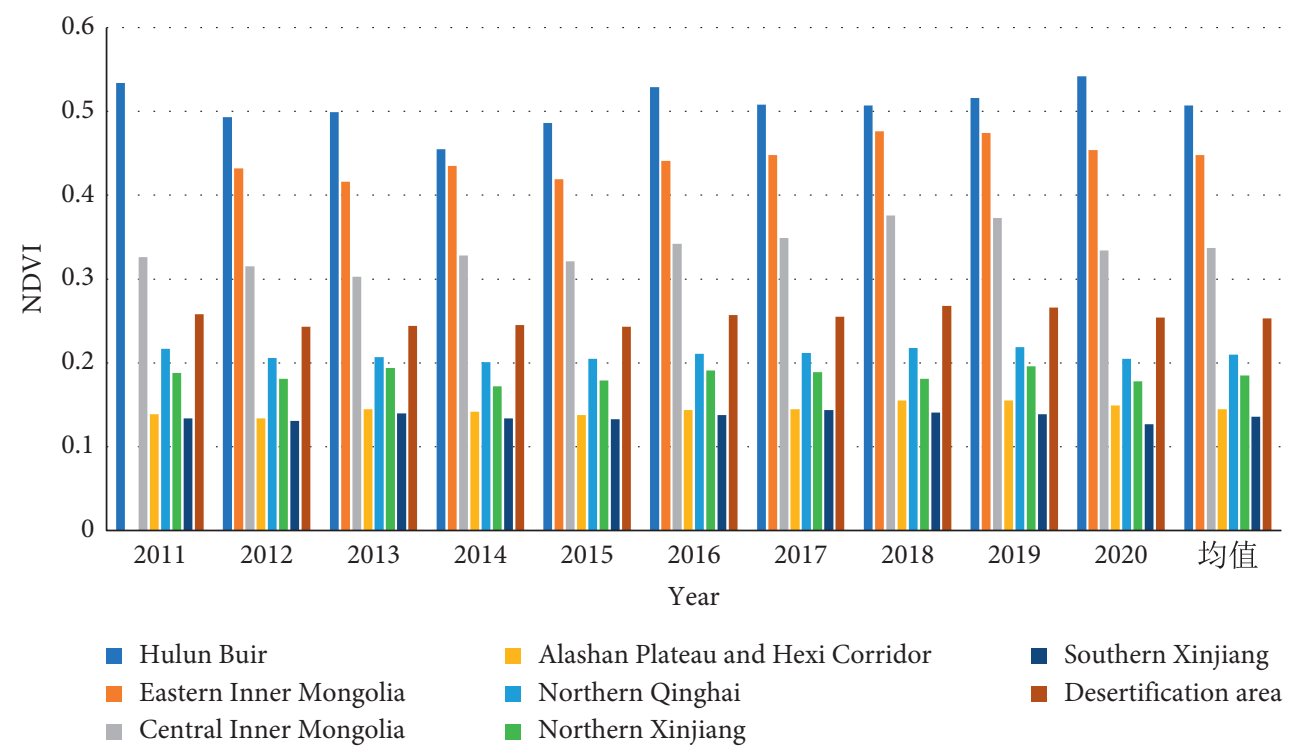

FIGURE 9: Analysis of the change trend of average NDVI in recent 10 years. 


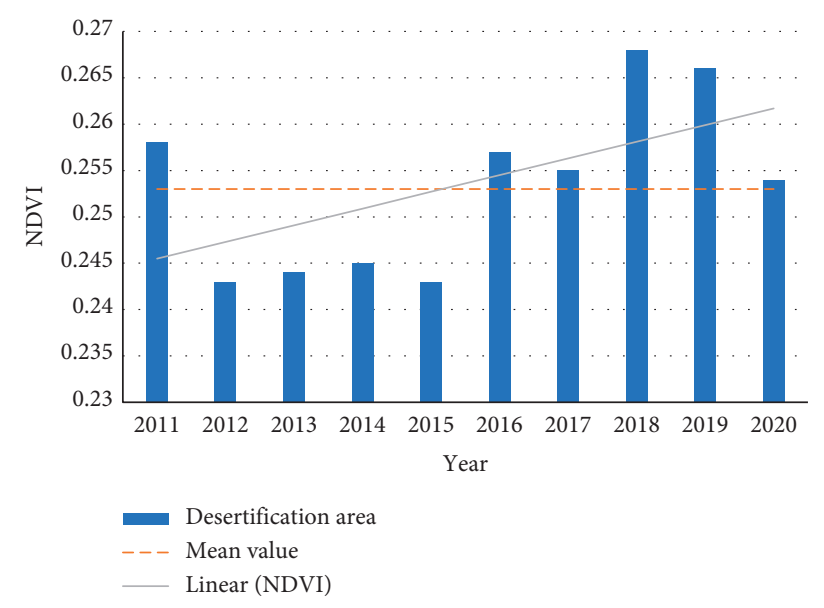

Figure 10: Changes of vegetation index in recent 10 years.

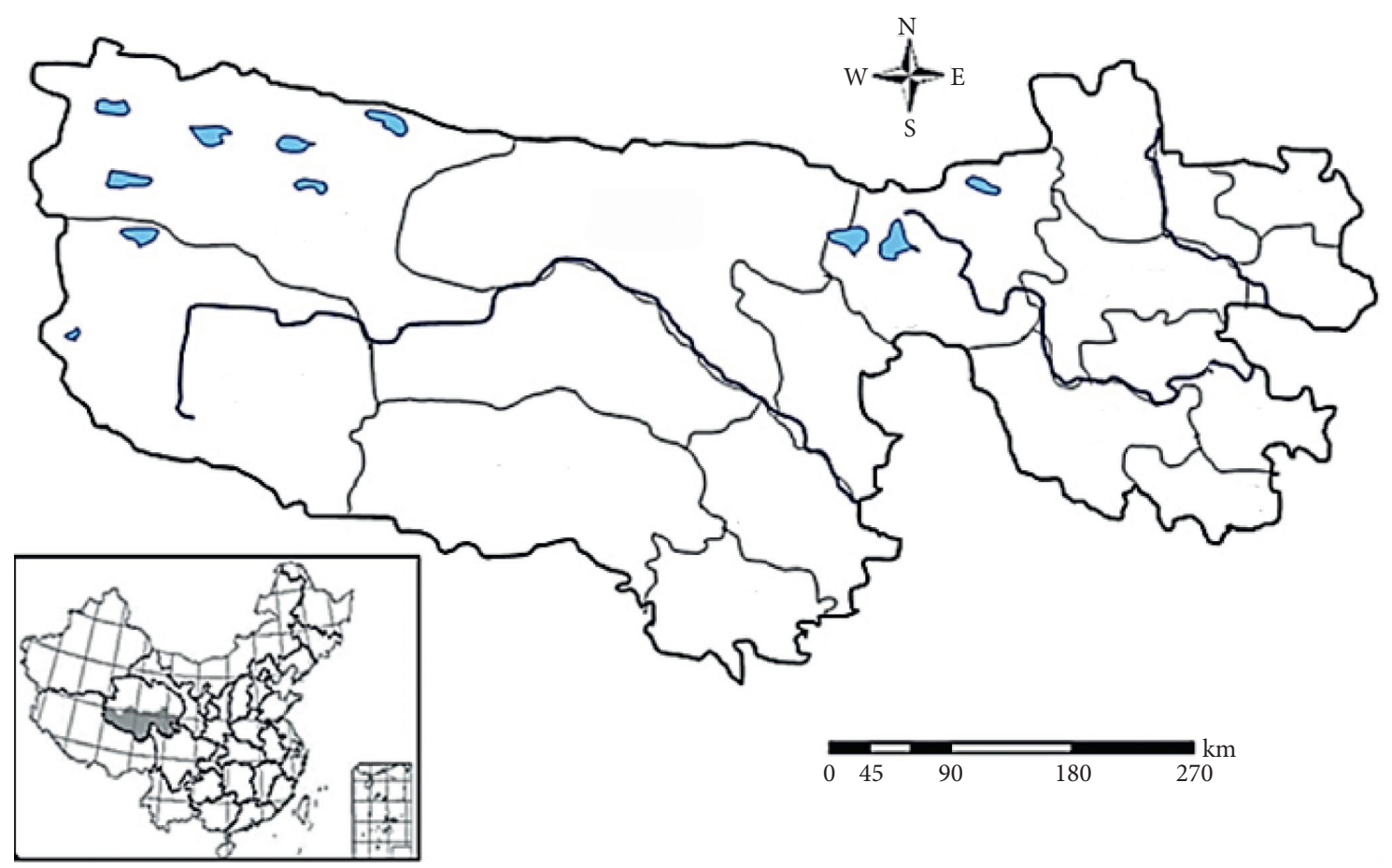

FIGURE 11: Geographic map of position.

Taking the land desertification in the source region of the Three Rivers in 2000 as the initial state, the model is run. The accuracy is tested by Kappa, and the calculated result is 0.864 , and the simulation result is ideal.

$$
\text { Kappa }=\frac{\left(P_{0}-P_{c}\right)}{\left(P_{p}-P_{c}\right)} .
$$

The goal is to unify the specifications, facilitate data processing, and avoid more troubles caused by the confusion of various data formats.

In equation (8), the ratio of drought stations can be used to evaluate the size and severity of drought range, $M$ refers to the total number of weather stations in the study area in the north, $J$ refers to different years, and $M J$ refers to the number of weather stations with drought in $J$ year.
In equation (10), Band 1 is the reflectivity in red band and Band 2 is the reflectivity in near infrared band. The greater the calculated NDVI value, the greater the vegetation density. The smaller the NDVI value, the smaller the vegetation density. In particular, the NDVI value ranges from -1 to 1 .

In equation (13), $P_{0}$ is the ratio of correct simulation, $P_{c}$ is the ratio of expected correct simulation in random case, and $P_{p}$ is the ratio of correct simulation in ideal classification case. Kappa $>0.75$ indicates that the accuracy of the model is good.

\subsection{Simulation Results}

3.5.1. Types of Land Ecosystems. As shown in Figure 12, most of the Sanjiangyuan region is grassland. Desertification land accounts for $9 \%$ of the total area. 
TABLe 6: Partially standardized data.

\begin{tabular}{lccc}
\hline Month & NDVI & Precipitation & Temperature \\
\hline $2000-01$ & 0.085106 & 0.003344 & 0.124879 \\
$2000-02$ & 0.085106 & 0.041033 & 0.396034 \\
$2000-03$ & 0.271277 & 0.211556 & 0.683783 \\
$2000-04$ & 0.558511 & 0.184884 & 0.898734 \\
$\ldots$ & $\ldots$ & $\ldots$ & $\ldots$ \\
\hline
\end{tabular}

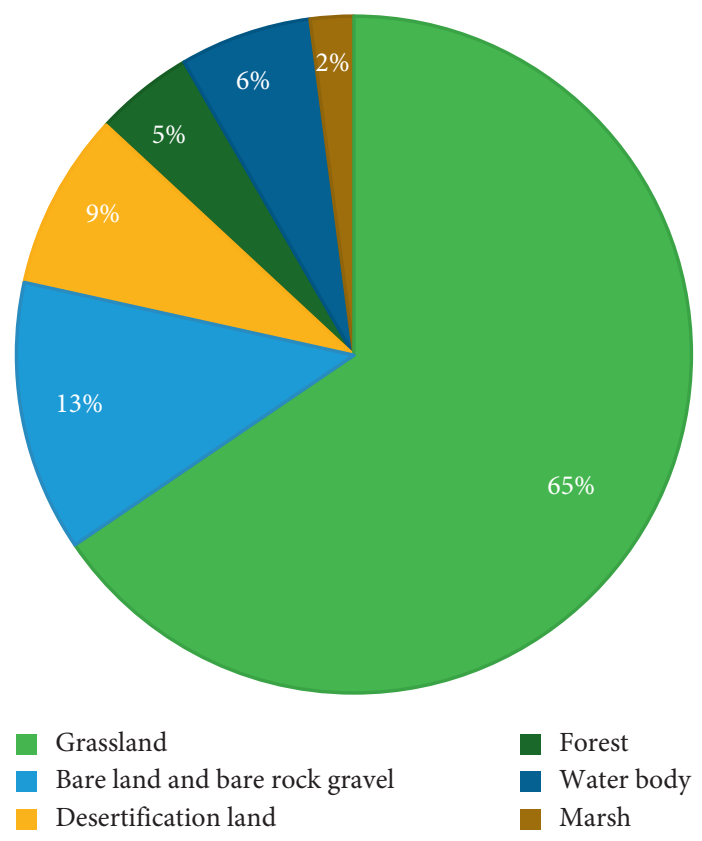

Figure 12: Statistical table of ecosystem type area in Sanjiangyuan.

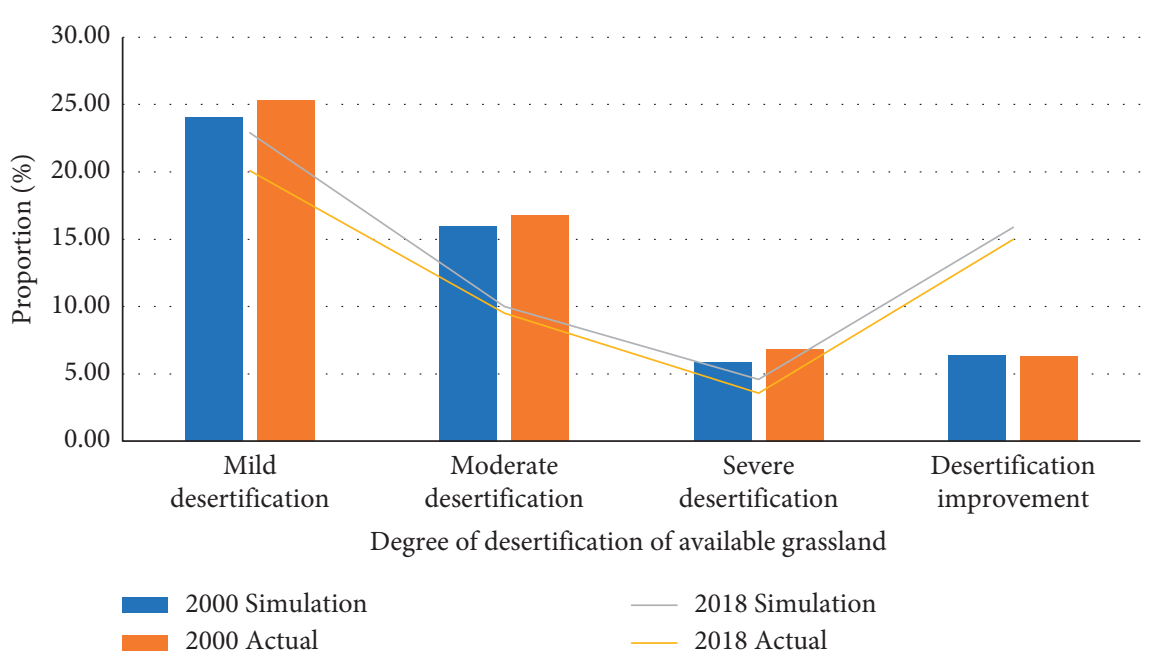

FIGURE 13: Desertification degree of available grassland.

3.5.2. Simulation Test Comparisons. In recent years, the ecosystem of Sanjiangyuan has been seriously damaged. Besides desertified land, nearly $70 \%$ of grassland is gradually desertified, and the annual desertification rate is maintained at $2.3 \%$.

(1) Land Desertification in Sanjiangyuan Region. We compare the desertification situation in 2000 and 2018 tested by the model with the actual desertification situation in 2000 and 2018. It can be found that the results tested by our simulation system are not much different from the actual results. The average difference between the simulation test in 2000 and the actual monitoring results is 0.78 , while the average difference between the simulation test and the actual monitoring results in 2018 is 1.31. The specific desertification statistics of available grassland are shown in Figure 13. 


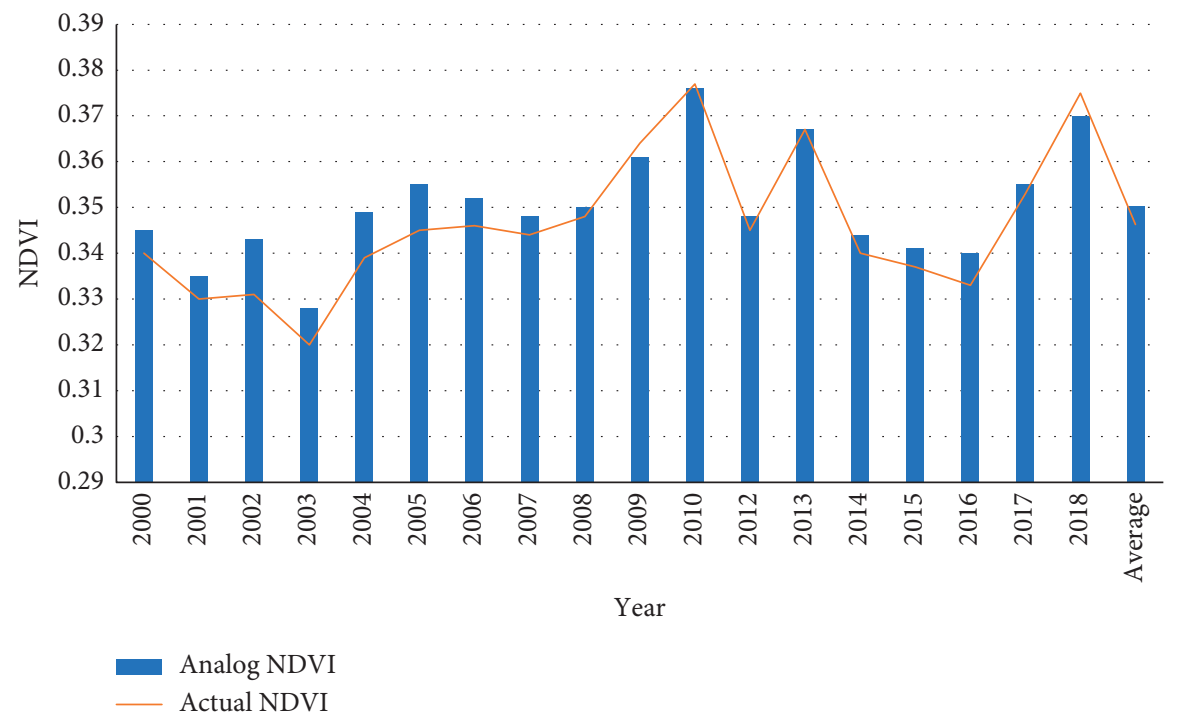

FIgURE 14: Interannual variation of NDVI.

(2) Interannual Variation of NDVI in the Source Region of the Three Rivers. The interannual changes of NDVI in 2000 and 2018 tested by the model are compared with the actual situation. It can be found from the figure that from 2000 to 2008, the simulated situation is quite different from the actual situation, and the difference from 2009 to 2018 is very small. The average annual NDVI in the simulation test is 0.350 , and the average annual NDVI in actual situation is 0.346. The details are shown in Figure 14.

The model designed by us runs very well and has little difference with the actual situation, which meets our research requirements.

\section{Conclusion}

(1) Most of the study area is covered by desert. In the past 10 years, the general trend of desertification has gradually decreased, and the ecological environment has gradually improved. The percentage of nondesertification has increased from $36.91 \%$ in 1991 to $44.46 \%$ in 2020 , an increase of $7.55 \%$. Extremely severe desertification increased from $21.72 \%$ to $24.25 \%$, an increase of $2.53 \%$.

(2) The annual and seasonal variation trend of SPEI in the northern study area decreased as a whole, with a decrease area of $74 \%$. The drought situation in the study area gradually improved.

(3) In recent ten years (2011-2020), the vegetation in China's land desertification areas has gradually grown well, and it is in the best state in 2018. The NDVI index value has increased by $5.9 \%$ compared with the average value in the past ten years. Land desertification has been controlled in China.

(4) The simulation test of land desertification in the source region of the Three Rivers has a good performance, and the difference between the test results and the actual results is basically very small, and the overall desertification trend in the source region of the Three Rivers is controlled.

The above data and methods in this paper are suitable for studying the spatial and temporal distribution characteristics of land desertification, but there are still some shortcomings and needs to be refined.

\section{Data Availability}

The experimental data used to support the findings of this study are available from the corresponding author upon request.

\section{Conflicts of Interest}

The author declares that there are no conflicts of interest regarding this work.

\section{Acknowledgments}

This work was sponsored by Jilin Provincial Department of Education (JJKH20191267KJ).

\section{References}

[1] T. Wang, W. Wu, and X. Xue, "Time-space evolution of desertification land in northern China," Journal of Desert Research, vol. 23, no. 3, pp. 24-29, 2003.

[2] Y. Zhang, Z. Chen, B. Z. X. Luo et al., "Land desertification monitoring and assessment in Yulin of Northwest China using remote sensing and geographic information systems (GIS)," Environmental Monitoring and Assessment, vol. 147, no. 1-3, pp. 327-337, 2008.

[3] K. Liu, W. H. Xu, Z. Y. Ouyang, and A. W. Jing, "GIS-based assessment on sensitivity to land desertification in Gansu province," Bulletin of Soil and Water Conservation, vol. 22, no. 5, pp. 29-31, 2002.

[4] L. Zhang, L. Yue, and B. Xia, "The study of land desertification in transitional zones between the MU US Desert and the Loess 
Plateau using RS and GIS? a case study of the Yulin region," Environmental Geology, vol. 44, no. 5, pp. 530-534, 2003.

[5] Y. Qi, Y. M. Wang, J. H. Wang, and C. Z. Yan, "Analysis on desertification dynamics based on remote sensing and GISexampled in Yanchi county, Ningxia," Journal of Desert Research, vol. 30, no. 4, pp. 862-880, 2003.

[6] H. U. Meng-Jun, L. H. Tian, D. S. Zhang, and Z. Na, "Study on dynamic changes of aeolian desertification lands around Qinghai lake in recent 30Years based on remote sensing and GIS," Journal of Desert Research, vol. 32, no. 4, pp. 901-909, 2012.

[7] M. Santini, G. Caccamo, A. Laurenti, S. Noce, and R. Valentini, "A multi-component GIS framework for desertification risk assessment by an integrated index," Applied Geography, vol. 30, no. 3, pp. 394-415, 2010.

[8] Z. J. Sha, Y. N. Zeng, L. Q. Li, M. H. Zhou, G. C. Cao, and P. Yang, "Dynamic monitoring of land desertification by RS and GIS - a case study in Longyangxia Reservoir area," Arid Land Geography, vol. 2013, no. 1, pp. 274-278, 2000.

[9] X. W. Liu et al., "A Web GIS application of desertification status of Ruoergai area," Advanced Materials Research, vol. 2014, pp. 838-841, 2014.

[10] A. Gad and I. Lotfy, "Use of remote sensing and GIS in mapping the environmental sensitivity areas for desertification of Egyptian territory," Earth Discussions, vol. 3, no. 2, pp. 654-660, 2008.

[11] J. Grunblatt, W. K. Ottichilo, and R. K. Sinange, "A GIS approach to desertification assessment and mapping," Journal of Arid Environments, vol. 23, no. 1, pp. 81-102, 1992.

[12] D. M. Song, G. X. Wang, C. Shen, and J. Wang, "Desertification evolution prediction for lake area of Minqin oasis based on integration of GIS and cellular automata," Science of Cold and Arid Regions (English Version), vol. 4, no. 3, pp. 222-228, 2012.

[13] A. S. Hadeel, M. T. Jabbar, and X. Chen, "Application of remote sensing and GIS in the study of environmental sensitivity to desertification: a case study in Basrah Province, southern part of Iraq," Applied Geomatics, vol. 2, no. 3, pp. 101-112, 2010.

[14] X. L. Mao, P. X. Zhao, D. X. Wang, W. Z. Li, and S. M. Liu, "Nonsupervising digital classification and GIS in the dynamic monitoring of soil desertification application," Journal of Northwest Forestry University, vol. 20, no. 3, pp. 6-9, 2005.

[15] W. Xu, "Quantitative estimation of desertification degree based on RS and GIS in mu us sandland, inner Mongolia," Scientia Silvae Sinicae, vol. 43, no. 5, pp. 48-53, 2007.

[16] C. S. Jarnevich, T. R. Holcombe, D. T. Barnett, T. J. Stohlgren, and J. T. Kartesz, "Forecasting weed distributions using climate data: a GIS early warning tool," Invasive Plant Science and Management, vol. 3, no. 4, pp. 365-375, 2017.

[17] C. Leake and J. Malczewski, "GIS and multicriteria decision analysis," Journal of the Operational Research Society, vol. 51, no. 2 , p. $247,2000$.

[18] J. Hansen, R. Ruedy, J. Glascoe, and M. Sato, "GISS analysis of surface temperature change," Journal of Geophysical Research: Atmosphere, vol. 104, no. D24, pp. 30997-31022, 1999.

[19] M. Wheatley, J. T. Fisher, K. Larsen, L. Joseph, and B. Stan, "Using GIS to relate small mammal abundance and landscape structure at multiple spatial extents: the northern flying squirrel in Alberta, Canada," Journal of Applied Ecology, vol. 42, no. 3, pp. 577-586, 2010.

[20] A. Facchinelli, E. Sacchi, and L. Mallen, "Multivariate statistical and GIS-based approach to identify heavy metal sources in soils," Environmental Pollution, vol. 114, no. 3, pp. 313-324, 2001.

[21] G. Cmara, R. C. M. Souza, U. M. Freitas, M. F. Ubirajara, and G. Juan, "SPRING: integrating remote sensing and GIS with object-oriented data modelling," Computers \& Graphics, vol. 15, no. 6, pp. 13-22, 1996.

[22] L. ü a Guo-Nian, G. Z. Ping, S. H. Sheng, and N. X. Su, "GISbased logistic regression for landslide susceptibility mapping of the Zhongxian segment in the Three Gorges area, China," Geomorphology, vol. 115, no. 1-2, pp. 23-31, 2010.

[23] J. Malczewski, "GIS-based multicriteria decision analysis: a survey of the literature," International Journal of Geographical Information Science, vol. 20, no. 7, pp. 703-726, 2006.

[24] M. Stuiver, P. M. Grootes, and T. F. Braziunas, "The GISP2 $\delta 180$ climate record of the past 16,500 years and the role of the sun, ocean, and volcanoes," Quaternary Research, vol. 44, no. 3, pp. 341-354, 1995.

[25] G. Dc, "Manipulating cattle distribution with salt and water in large arid-land pastures: a GPS/GIS assessment," Applied Animal Behaviour Science, vol. 73, no. 4, pp. 251-262, 2001. 